Social Semiotics, Vol. 11, No. 3, 2001

\title{
Metaphor and Metacommunication in Schizophrenic Language
}

\author{
JOHN FROW
}

Since the beginning of this century, psychiatrists and linguists, assuming a correlation between disordered talk and disordered cognition, have sought to devise language tests with diagnostic efficiency for mental 'illnesses'. Schizophrenia in particular has been assumed to be characterized by disorders of cohesion, of reference, and of symbolization. Much of this work is flawed by its a priori assumptions about the reality of the category of schizophrenia and about the relation between 'normal' (non-figurative, 'logical') and 'deviant' (figurative, 'magical') uses of language, as well as by particular methodological problems such as the failure to control for experimental context and for the effects of psychotropic drugs. Nevertheless, the debates within psychiatry and linguistics over communicative disorders have a good deal to tell us about the 'normal' uses of figurative language in social interaction. In particular, they raise complex questions about the metacommunicative functions of metaphor: How does figuratively coded language work to convey multiple simultaneous and sometimes contradictory messages? What kinds of discursive relations does it thereby establish or maintain or disrupt? How does it contribute to narrative cohesion, and are there tensions between figure and story? On what basis, if any, is it possible to distinguish between 'appropriate' and 'inappropriate' uses of metaphor?

\section{Part I}

My specific interest in this paper is in the theoretical and clinical construction of something called 'schizophrenic language'. Let me start by giving an example of the kind of talk that counts in the literature as problematic or deviant. I must stress that I make no claims about this decontextualized piece of text, which I have taken almost at random from an article on schizophasia (Rutter 1979: 357), other than that it illustrates a certain object of theoretical concern. The patient is responding to a question about the reasons for their entry into hospital:

You mean what class of amusements I would go for if I had the money though I never had any money in my life so therefore I would not know. They do not really bother me and never will bother me. Therefore I do not fit in this house at all. I should be led to the gate there by the elbow and given my jacket and coat and told to carry on the way I was carrying on because I never broke in you know. It was eighteen men that lived there the 
fairy told me and broke into that place themselves because its glass in that factory is exactly a thousand years old. Just the same as a castle now if you were paying rent for a castle for a thousand years you do not pay no more money for that castle it is your castle. That means everything within it is new over and over again. The only thing that you do pay for is you pay $£ 38$ every week if you keep more than thirty-two full-board lodgers paying five guineas each. That is the rules and laws of castledom. That form you gave me is excelsior form.

What is it that is perceived as problematic about such a piece of language? At the most general level, there is an assumption that its strangeness (whether this is inherent in the language itself or is an effect of its lack of fit with the context in which it is uttered) can be taken as a clue about the mental state of the speaker. Its apparent failure of narrative coherence is an index at once of an inability to put a story together, and of failure to handle symbolization in an appropriate manner. As Wing (1978: 110) puts it in speaking of the symptoms of 'intrinsic impairments' in schizophrenia, 'the individual does not seem able to think to a purpose, but goes off at a tangent owing to some unusual association to a chance stimulus, and this gives the impression of vagueness, confusion, and incoherence'. At a more specific level, a number of particular formal features may then be identified: idiosyncratic streams of association, perseverance on words or topics, vague generalization and use of abstractions, ellipsis, echolalia, literalness and concreteness; or alternatively: the use of highly figurative language without clear reference, use of neologisms or predilection words, telescoping of words, and glossomania, defined by Lecours \& Clément (1976: 524) as a 'production of sentences the verbal components of which are chosen (mainly) on the basis of phonological kinships to one another (alliteration, assonance, homophony, and so forth)'.

The assumption is not, in most cases, that schizophrenics speak a language peculiar to them, nor, usually, that schizophrenics lack competence in the formation of grammatically correct sentences, although some writers do postulate that schizophrenia is associated with a kind of aphasia. Rather, there is an assumption of a deficit in the production of meaning, either at the semantic level or at the level of narrative coherence and communicational adequacy. This is often understood as an information-processing deficit, or a deficit of reflexivity (an inability to edit speech production adequately). In whatever way the problem is defined, the hope is that a rigorous account of linguistic or communicative abnormalities will have diagnostic value.

Let me note a preliminary problem in the assumption of a defective use of language by schizophrenics, the sheer and mutually contradictory variety of 'deficits' observed, and the absence of a coherent theory of 'normal' usage against which to define deviations. Lorenz (1961: 603) notes that "Schizophrenic language" can be correctly designated as both concrete and as abstract; as restricted, impoverished, and as fluid, overideational; as empty of meaning and as overinclusive of meaning; as resembling prelogical thinking and as metaphoric and symbolic'. And Bleuler (1982: 591) observes that schizophrenic language uses may be intermittent, or not 
present at all, in many schizophrenics, or present in speech and not in writing, or present with some interlocutors but not others. There is thus, as Sass (1992: 175-176) puts it, considerable difficulty in knowing 'whether we are encountering a specifically linguistic disorder rather than, say, a more general cognitive or perceptual deficit, a certain social attitude or incapacity, a preoccupation with delusions or other abnormal ideas, or some combination of these'.

In what follows, I shall examine in some detail the more important ways in which 'schizophrenic language' is at once explained and postulated. These explanations take the form either of linguistic theories, of theories of the logic of figurality, or of theories of discursive disorders or strategies. First, however, I wish to undertake a brief excursus on the experimental conditions under which the phenomenon of schizophrenic language is observed.

In the first instance, the physical setting for almost all case studies is either the hospital or the clinic, and the observer is either a medical practitioner or someone operating with the approval of the medical authorities. The problem here is not just the distorting effects of this relation of unequal power (and its translation into effects of language), as well as the institutional erosion of time-sense and thus of the narratibility of subjects' lives. It has to do, more fundamentally, with the constitution of the diagnosis on the basis of which subjects are selected for observation; since disordered speech is already one of the markers of schizophrenia, there is an inherent danger of circularity in any analysis of subjects with this diagnosis. ${ }^{1}$

The other complicating factor is metabolic: in the case of long-term hospitalized patients, there is a significant possibility that their 'metabolic pathways' will have been affected by institutional conditions, and there is clear evidence that long-term hospitalization in itself has measurable results on speech (Coulter 1973: 11). But a still more significant factor is the effect of psychotropic drugs on speech production. Although in any study conducted from the 1960s onward there is an overwhelming likelihood that subjects will be under the influence of psychotropic medication, and although again there are clearly measurable distorting effects on speech, these effects are almost universally dismissed from consideration in the literature even when they are noted. ${ }^{2}$

Beyond the physical framework of hospitalization and medication, the predominant context within which craziness is understood and treated is a medical model of behaviour that is predicated on the metaphor of mental illness. Within this context, certain disordered behaviours are read as 'symptoms' of schizophrenia; these 'symptoms' are not bodily complaints, but are 'framed as the result of the application of a disease model to people's talk and conduct, their beliefs and communicated experiences' (Coulter 1973: 4), and they are then treated either as evidence of a disease process, or as the illness itself. As Coulter (1973: 8-9) argues, 'the disease model of the schizophrenias ... leads the researcher to assimilate the myriad of incomprehensible acts and utterances of insane people into the only explanatory framework which has traditionally had bestowed upon it the sanctity of "science": the physicalist framework'. As a consequence:

the psychopathologist interested in biochemical models of insanity, which 
postulate some organic dysfunction in the brains or bodies of diagnosed persons, will of necessity bypass the possibility that what he takes as 'symptoms' to be related back to allegedly determinant antecedents, are aspects of those people's communicative relationships and have a sense apart from their being produced by physical organs-i.e., an interpersonal meaning or significance.

The metaphor thus gives rise to a curiously self-confirming process by which the working assumption of an organic cause of the 'illness' (whether it be genetic, chemical or whatever) is then translated into the certain knowledge that schizophrenia is a genetically or chemically induced disease-with the clinical consequence that treatment can be conducted exclusively by a chemical regime and that the ill patient need not be 'heard' beyond the stage of diagnosis (cf. Leudar \& Thomas 2000). Thus, one of the most striking features of so much of the literature is the sheer inability of researchers and therapists to listen to what is being said to them, and so to recognize the narrative patterns by which patients' speech is organized.

Let me take as one case among innumerable others a discussion by John Benjamin (1946: 75-76) of the use of the interpretation of proverbs to discriminate thought disorders. Again and again in his account, literal and perfectly correct readings are described as 'stupid' or as 'evidence of mild mental deficiency', and imaginative, often quite powerful readings are dismissed out of hand. One 'disturbed' patient, for example, gives the following responses:

- To 'when the cat's away the mice will play', the response was: 'The last supper of Jesus, all those that kissed the novitia, the covitia. The political world is too much, we can't fight it, we can't see murder.'

- To 'don't cross your bridges till you come to them', the response was: 'Don't cross your bridges till you come to them is right. It's true. Oh, mother; oh, mother.'

- To 'a rolling stone gathers no moss', the response was: 'A rolling stone gathers no moss-Christ. Breaking chain stores all together. Independency.'

- To 'the proof of the pudding is in the eating', the response was: 'That's my pudding, doctor. All God give forgiveness. Oh, mamma, why did they make expensive weddings? Why don't they stay home, mamma?'

These responses are said to exhibit 'bizarre content, incoherence, peculiar sentence structure, obviously complex-determined sexual and religious preoccupations, a clang-determined neologism, and so on'; they constitute 'a refusal' of interpretation, and all answers 'illustrate the highest possible degree of literalness in the approach of the patient to the assigned task'. What is at issue here is deviation from a pre-supposed norm of desymbolization of the figurative language of the proverbs; or, more precisely, a norm that prescribes the ability to move both ways along a spectrum between the literal and the figurative-since some proverbs, like 'discretion is the better part of valour', seem to require paraphrase at a lower level of abstraction. But what is really at stake, I suggest, is the analyst's ability to listen to 
and to understand the enunciative force (the interactional content) of the figurative expressions employed by the subjects he is studying.

\section{Part II}

The theories of schizophrenic speech disorders that I now go on to discuss are anomalous to the extent that they do listen to what their subjects say-although the quality of their attention is one of the things that I shall be examining. The first set comprises those very heterogeneous theories that posit a formal deficit in the production of language by schizophrenics (the major overviews are Schwartz (1982) and Rieber \& Vetter (1994); and, from a semiotic perspective, Wróbel (1990)). All such theories, I argue, are built around an implicit model of communicative normalcy that corresponds to the Gricean maxims of economy, truth, relevance, and transparency (Grice 1989). ${ }^{3}$ The formal structure of such theories is thus the denunciation of excess. Chaika (1974: 270) accordingly writes that 'What is most interesting [in the piece of language she is discussing] is the richness of the associations. The patient is paying attention to far too many of the semantic features of a word. In normal discourse, one only notes those semantic features that fit the context.' In case we should think that richness of associations might be a virtue rather than a failing, she then draws an explicit, although somewhat uncomfortable, parallel with poetic language:

Preoccupation with definition, abnormal rhyming, and inappropriate word associating have long been recognised as features of schizophrenic speech ... In fact, typically they are the concern of poets. Of course, poets make these their concern by especially focusing on them. In their usual conversation, poets, like most people, ignore such features or, at least, they do not allow them to interfere with the topic at hand in their surface utterances. The schizophrenic, however, does not seem to be able to suppress his notice of the features of words. (Chaika 1974: 269)

How, we might ask, does the poet's activity, qua poet, of 'especially focusing on' the materiality of words differ from the schizophrenic's non-suppression of his notice of such features? Chaika does not say, nor, within the limits of the model of communicative competence she is using, could she.

My major example of a linguistic analysis of schizophrenic speech as formally deficient is Sherry Rochester and Jim Martin's Crazy Talk-perhaps the most sophisticated of the many such studies. Their initial hypothesis 'that many of the incoherent stretches in schizophrenic discourse might reflect the speaker responding to him- or herself' (Rochester \& Martin 1979: 51-52) leads them to focus on an analysis of the syntagmatic and lexical structures that organize textual cohesion. ${ }^{4}$ More precisely, cohesion, in their Hallidayan model, is seen as a semantic relation that is coded through lexical or grammatical forms. They identify five types of cohesive tie: reference, both exophoric and endophoric; substitution; ellipsis; conjunction; and lexical repetition. Such a focus allows them to analyze both situational relevance and internal cohesiveness, and they work from an expectation that 
schizophrenic patients will be relatively insensitive to social contexts and that they will display little variation in cohesive ties across contexts. This is a model, of course, of good narrative structure.

The method Rochester and Martin employ is that of a close statistical analysis of clause length, clause boundaries, clause linkage, and phoric reference between nominal groups, with data taken from an unstructured interview, a re-telling of an oral narrative, and descriptions and interpretations of 10 cartoon pictures. What they find is a low reliance by schizophrenics on cohesion in narrative, and a high reliance on lexical repetition. Their subjects' focus is on signifiers rather than on signifieds or on contextual relevance, and Rochester and Martin explain this in terms of a heavy reliance on paradigmatic associations and phonic repetition to tie language together (as in 'Since they've attacked Pearl Harbour, now they will attack Diamond Harbour or Gold Harbour', or in the definition of 'rare' meat as 'uncommon' meat) (Rochester \& Martin 1979: 92). They suggest that 'the schizophrenic speaker's sentence-to-sentence or clause-to-clause relationships are based on "concrete" or literal word meanings that are independent of the extended semantic relationships of the discourse text' (ibid). More generally, schizophrenic speakers are said to be relatively insensitive to variations in context, and they presume the identity of discursive participants wherever possible: that is, they display a failure of awareness of the otherness of the listener, and of the need to supply information to bridge that gap.

This analysis supposes a norm of communicative and narrative competence that is invariant in all contexts, including that of hospitalization. Thus, the authors write of one sample of text: 'The use of the same or similar sentence-frames and the use of parallel prosodic strings suggests that the speaker is playing with words rather than forming them into vehicles for communication. The speaker is somehow failing to create an adequate sequence of propositions, though the propositions considered individually are understandable' (Rochester \& Martin 1979: 127). Similarly, Rochester and Martin assume that schizophrenic uses of figurative materials are deficient, without, however, ever seeking themselves to develop an explicit norm of what might constitute the appropriate ways of handling the figurative dimension of language.

My second major paradigm, which understands schizophrenic language as being organized by what Silvano Arieti calls a 'palaeologic', does directly address this question. Arieti's argument is based on an evolutionist understanding of human ontogeny and phylogeny: the forms of schizophrenic thinking, he writes, are 'obsolete, archaic mechanisms, buried long ago in unconscious processes', and the logic that schizophrenics employ 'is the same as that which is followed in dreams, in other forms of autistic thinking, and in many manifestations of men living in prehistorical and certain other cultures' (Arieti 1955: 186). This 'palaeologic' fits on a spectrum of deviations from 'pure logical Aristotelian thought', a spectrum of 'intellectual distortions' (189), and Arieti is quite explicit about the norm of evolutionary progress that informs this conception:

It seems to me irrefutable that palaeologic thought per se must be con- 
sidered inferior to the Aristotelian. It is much less reliable, it induces errors and the perpetuation of these errors, which could be avoided with Aristotelian thought. Unless we revise our philosophical concept of progress, we have to consider Aristotelian thought as being superior to the palaeologic. The achievements in which humanity takes pride could not have been attained if the palaeologic method of thought had not been the prevalent one. The tendency of such thought to occur in early childhood, in a dream state, and in pathological conditions, when our higher mental functions have not yet developed or cannot be used, seems to indicate irrefutably that it is a way of thinking which does not require our highest levels of integration. If we accept the evolutionary point of view in biology, and correspondingly a comparative developmental approach in psychology, we also have to accept the notion that intermediary stages once existed between some apes or ape-like species and the races of men who live today. Presumably these intermediary races of men thought palaeologically. (Arieti 1955: 269)

At the core of palaeologic thought is a notion that Arieti takes from von Domarus (1946) of a conception of logical identity as being based on identical predicates rather than only on identical subjects: $\mathrm{A}$ is $x, \mathrm{~B}$ is $x$, therefore $\mathrm{A}$ is $\mathrm{B}$ (men die, grass dies, therefore men are grass). What Arieti does not consider, however, is that this mode of identification can alternatively be understood not as a syllogistic error, but as the deliberately fictional logic of metaphorical identity ('all flesh is grass').

In addition to this logic of predicational identity, Arieti posits a logic of the signifier that is peculiar to schizophrenics and other palaeologicians: 'For the person who thinks palaeologically, the verbal symbols cease to be representative of a group or of a class, but are representative only of the specific objects under discussion' (1955: 211), and this 'tightness to the denotation prevents the schizophrenic from using figurative or metaphorical language' (213). Like Chaika, Arieti makes the ambivalent comparison with poetic language: 'The primitive and the schizophrenic use metaphors out of necessity, not for aesthetic reasons. The artist may exploit archaic processes to intensify the emotional tone of his expression, but at the same time will retain that power of abstraction which has been lost by the schizophrenic and which has not been sufficiently used by the primitive' (1955: 215).

The other dimension of this logic of the signifier is a kind of magical thinking that identifies homonyms as having a common or associated meaning, and more generally identifies ideas on the basis of physical contiguity. Freud makes a similar argument about the nature of primary-process thinking, which blurs the distinction between the signifier (the 'idea of the word') and the signified (the 'idea of the thing') in such a way that the idea of the word comes to take the place of the thing-presentation. Thus, for Freud (1957: 199; cf. Laffel 1965: 158), 'in schizophrenia words are subjected to the same process as that which makes the dream images out of latent dream-thoughts - to what we have called the primary psychical process. They undergo condensation, and by means of displacement transfer their cathexes to one another in their entirety. The process may go so far 
that a single word, if it is specially suitable on account of its numerous connections, takes over the representation of a whole train of thought'. Kurt Goldstein (1946: 26-27) likewise argues that 'a word when used by a schizophrenic appears as part of an object or a situation, not as a representative of it', and he draws from this an interesting conclusion: that these defects are not expressions of symbolic or metaphoric thinking, but the opposite. Symbolic thought, he argues, 'belongs to higher forms of thinking which are usually impaired in schizophrenia, and ... the observable phenomena are understandable from the point of view that we are dealing with a very concrete form of thinking'. This, I think, neatly undercuts some of the crudeness of Arieti's thinking about the magical status of figurative thinking, since the notion of 'concrete' thinking has to do not with an incapacity for lexical abstraction but with a failure of logical typing. It is a case that is taken up by David Forrest, who argues that what is manifested in much schizophrenic language is a lack of awareness and control of the reification of the signifier: following Bateson, Forrest (1965: 12) writes that the schizophrenic uses unlabelled metaphors. The problem is thus not the 'concreteness' of the language - in fact, 'there is a case for considering abstract language a pathological variant of the specific ways of speech'. The language used by schizophrenics is not in itself inherently abstract or concrete, but it is characterized by a lack of appropriate distinction between the two. (A similar argument is made by Jaynes (1976: 420-422) in his account of the archaic mental organization of schizophrenia.)

This brings me to my third paradigm, which involves a series of arguments about the consequences of difficulties in the metacommunicative processes that allow distinctions to be made between different logical levels or allow appropriate choices to be made about the relation of speech to situation; typically, these arguments entail a shift from an account of formal linguistic deficits to an account of communicational deficits. For Bertram Cohen (1978: 313), disturbances in language usage 'are not impairments in language per se but are impairments of interpersonal communication. Thus, measures of communicability are much more effective discriminators of schizophrenia from normal (or neurotic) speech than are measures of linguistic structure, style, or content.' Making a similar argument, Dawson et al. (1980: 83-84) suggest 'that an early and common deficit in the development of schizophrenia is an inability or decay in the ability (1) to encode the characteristics of others, particularly those characteristics that require active, continuous monitoring ...; and (2) to integrate recent verbal information in attempts to communicate'.

Let me note, in passing, the possible deficiencies of any theory of communication understood as the activity of a conscious, singular, and intentional transmitting subject, and, without pursuing this any further, move on to the major theorist within this paradigm, Gregory Bateson. The theory of logical types that Bateson adapts from Russell and Whitehead's elaboration of the paradoxes of set theory argues for the multiplicity of logically differentiated levels and modes of communication that constitute talk and writing of all kinds. Language, on the argument of Bateson and his collaborators, constantly frames, labels, brackets, and comments on other levels of language, plays around with the distinction between the fictional and the nonfictional, shifts between propositions that require to be taken at face value and 
propositions that require to be displaced into another explanatory order, and confirms or falsifies the cues, the situational indicators, that identify kinds of talk. Schizophrenics have weaknesses in three of the central areas of discrimination of communicational modes: they have difficulty in assigning the correct communicational mode to the messages they receive from other persons, to the messages which they themselves utter, and to their own thoughts, sensations and percepts. These weaknesses include a problem in the handling of metaphor: not in the fact of extensive use of metaphor, since for Bateson metaphor is a central tool of all human cognition, but in the use of 'unlabelled' metaphors. The schizophrenic 'has specific difficulty in handling signals of that class whose members assign logical types to other signals' (Bateson et al. 1973: 177): a difficulty at the level of metadiscourse, such that in double-bind situations, where they are in receipt of simultaneous and conflicting messages, they are unable to make an appropriate metacommunicative judgement.

This weakness may, however, be turned into a defence; and, in the latter part of his argument, Bateson shifts from an account of metacommunicative deficit to an account of the strategic use of unlabelled metaphor as a way of slipping out of the double bind by evading responsibility for statements. The schizophrenic who interprets a social greeting as a threat or a sexual invitation is either failing or is deliberately (in some sense of that word) refusing to make a situationally correct judgement of discursive modality. Schizophrenic psychosis then, in Bateson's summary, 'seems, in part, a way of dealing with double-bind situations to overcome their inhibiting and controlling effect. The psychotic patient may make astute, pithy, often metaphorical remarks that reveal an insight into the forces binding him. Contrariwise, he may become rather expert in setting double-bind situations himself' (Bateson et al. 1973: 192).

With this shift, Bateson moves into my fourth paradigm, centred on the strategic uses of metacommunication (or of the refusal of communication). For the key figure here, Bateson's erstwhile colleague Jay Haley, the schizophrenic exemplifies a fourfold possibility of the thwarting of communication, by their ability to avoid defining their relationship to another person through the negation any one of the four elements in the transmission of a message: the schizophrenic 'can (a) deny that he communicated something, (b) deny that something was communicated, (c) deny that it was communicated to the other person, or (d) deny the context in which it was communicated' (Haley 1963: 89).

Within an interactional perspective, the symptoms of schizophrenia can be described 'as indicating a pathology centering around a disjunction between the person's messages and the qualifications of those messages' (Haley 1963: 91): that is, there is a systematic negation of what the schizophrenic says by the ways in which he/she qualifies what they say. Indeed, there is normally a double denial involved here: both a denial that the schizophrenic is saying something, and a denial of this denial. Needing a match for a cigarette, the schizophrenic will not only not ask for one, but will act as though the cigarette is something to be stared at rather than to be smoked; or, in a room with a stranger, will not only not talk, but will seem excessively pre-occupied, as a way of denying the apparently negative relationship. 
They will give their name but the name is false, but it is given in a way that indicates this; or a hospitalized patient 'makes a congruent statement about the context, saying it is a hospital, but qualifies this with the statement that all he needs to do is give up cigarettes. He promptly negates this statement that implies there is nothing really wrong with him by saying he is a spatial condition from outer space' (Haley 1963: 96). In such circumstances, the therapist must take himself/herself as a part of the context of communication; an objectifying empirical analysis will miss the point precisely to the extent that it ignores its own relation to the interactive dimension of schizophrenic talk.

\section{Part III}

Theories of language disorder in patients diagnosed schizophrenic can be accommodated either within a medical model of illness or a psychosocial model that thinks of behaviour as being in some sense chosen. Predominantly, in our culture, they are diagnosed within the medical model, often within a modified version of it that posits a malfunction of the information-processing centres in the brain. The choice of explanatory metaphor, as I argued earlier, sets the ground for the types of explanation and interaction open to the analyst. As Shoham-Salomon (1985: 451) writes, 'It follows logically from the medical model that schizophrenic persons, even when performing acts that could be interpreted as normal, are perceived as exercising little specific freedom of choice, as driven by their mental illness, and as acting endogenously rather than instrumentally'. Conversely, it follows 'logically' from a psychosocial model that schizophrenic persons can be judged as rational actors driven to irrational actions for which they can in some sense be held responsible. Within the medical model, there is no necessity to pay attention to the content of a patient's discourse, since speech is no more than symptomatic; but note that, of the theorists I have discussed, even the one who seems to take schizophrenic speech acts most seriously, Jay Haley, is essentially interested in the strategic force of these acts rather than in the statements being made. If I say that I am a condition from outer space, or if I talk about castles in a context that suggests I am talking about mental hospitals, it is the interactional function of these propositions that is taken seriously rather than the way they might work as allegories of my situation.

The conclusions that I wish to draw from this very summary analysis are minimal and rather tentative. Let me start with a point made in a recent paper by Ted Cohen (1997: 223): that 'there is no infallible sign that any given expression, spoken or written, is a metaphor'. And let me follow this with what I think is its corollary: that although our very sense of figurative language depends on the drawing of lines, however contingent and transient, between the figurative and the literal, there can, by the very nature of language, be no such thing as a purely literal language, a degree zero of figuration. Yet this old fantasy haunts the whole history of Western thought and, centrally, the history of science. To say that it is a fantasy is not to denounce this project, but it is to insist that it has its proper place. Where it does damage is in those occasions in which it constructs its other, the unreason against which it 
defines itself; and in which this labour of definition then turns into an activity of punishment.

What I take from my long march through the literature on schizophrenic language is a sense of the power and prevalence of the Gricean maxims, those normative statements that proclaim that language is supposed to work transparently, economically, truthfully, and to the point. Now, there are two ways of reading these maxims: as an explanation of the communicative norms from which all actual language use deviates; or as genuinely normative statements, ought-statements, which embody that destructive fantasy of literalness of which I have been speaking. ${ }^{5}$ I have no doubt that it is this second, normative usage that informs virtually all models of normal and abnormal communication. It is a model that at once produces and depends upon the pathologization of deviant uses of language; and it is a model that implicitly renders pathological all of the sliding, shifting, tricky, seductive, projective and complexly indirect ways in which - if you will forgive the metaphor-real language across all genres really works.

University of Edinburgh

\section{Acknowledgements}

My thanks to Christine Alavi, who has had a major role in forming my thinking about schizophrenia. An earlier version of this paper was given at a conference on metaphor and narrative convened by Mike Hanne in Auckland in 1996.

\section{Notes}

[1] On the methodological problem of selection and comparison, cf. Manschreck et al. (1979: 595).

[2] cf. Levy (1968: 431): 'It seems likely that the drug does have profound effects on speech and that any attempt to analyze linguistic performance of patients without taking into account the drugs which they are having, is bound to be meaningless'. Also, cf. Spohn (1973) and Hymowitz \& Spohn (1980).

[3] Grice (1989: 26-27) posits four categories forming the Cooperative Principle that makes conversations sustainable: to that of quantity correspond implied maxims about the appropriate amount of information to be contributed; to that of quality, maxims governing the truth of one's utterance; to that of relation, a maxim that the utterance must be situationally relevant; and to that of manner, a 'supermaxim'-'be perspicuous' - and various maxims governing the clarity of the utterance.

[4] For a later study of cohesion ties, cf. Fine (1995).

[5] Grice himself explicitly claims only that the maxims are necessary for the comprehension of 'conversational implicatures', which constitute deviations from them, as in the case of figurative language; but he also foreshadows a more general claim for the norms he describes 'not merely as something that all or most do in fact follow but as something that it is reasonable for us to follow, that we should not abandon' (Grice 1989: 29).

\section{References}

Arieti S 1955 Interpretation of Schizophrenia New York Robert Brunner.

Bateson G, D Jackson, J Haley \& J Weakland 1973 'Towards a theory of schizophrenia', in G Bateson (ed) Steps to an Ecology of Mind St Albans Paladin 173-198. 
Benjamin J 1946 'A method for distinguishing and evaluating formal thinking disorders in schizophrenia', in JS Kasanin (ed) Language and Thought in Schizophrenia Berkeley CA University of California Press 65-90.

Bleuler M 1982 'Inconstancy of schizophrenic language and symptoms', The Behavioural and Brain Sciences 5591.

Chaika E 1974 'A linguist looks at "schizophrenic" language', Brain and Language 1 257-276.

Cohen B 1978 'Self-editing deficits in schizophrenia', in LC Wynne, RL Cromwell \& S Matthysse (eds) The Nature of Schizophrenia: New Approaches to Research and Treatment New York Wiley 313-319.

Cohen T 1997 'Metaphor, feeling, and narrative', Philosophy and Literature 21 223-244.

Coulter J 1973 Approaches to Insanity: A Philosophical and Sociological Study London Martin Robertson.

Dawson DFL, G Bartolucci \& HM Blum 1980 'Language and schizophrenia: towards a synthesis', Comprehensive Psychiatry 21 81-90.

Fine J 1995 'Towards understanding and studying cohesion in schizophrenic speech', Applied Psycholinguistics 16 25-41.

Forrest DV 1965 'Poiesis and the language of schizophrenia', Psychiatry 28 1-18.

Freud S 1957 (1915) 'The unconscious', in J Strachey (ed, trans) The Standard Edition of the Complete Psychological Works of Sigmund Freud London The Hogarth Press Vol XIV 159-215.

Goldstein K 1946 'Methodological approach to the study of schizophrenic thought disorder', in JS Kasanin (ed) Language and Thought in Schizophrenia Berkeley CA University of California Press 17-40.

Grice P 1989 'Logic and conversation', Studies in the Way of Words Cambridge MA Harvard University Press 22-40.

Haley J 1963 Strategies of Psychotherapy New York Grune and Stratton.

Hymowitz P \& H Spohn 1980 'The effects of antipsychotic medication on the linguistic ability of schizophrenics', The Fournal of Nervous and Mental Disease 168 287-296.

Jaynes J 1976 The Origin of Consciousness in the Breakdown of the Bicameral Mind Boston MA Houghton Mifflin.

Laffel J 1965 Pathological and Normal Language New York Atherton Press.

Lecours AR \& MV Clément 1976 'Schizophasia and jargonophasia: a comparative description with comments on Chaika's and Fromkin's respective looks at "schizophrenic' language" ', Brain and Language 3 516-565.

Leudar I \& P Thomas 2000 Voices of Reason, Voices of Insanity: Studies of Verbal Hallucinations London Routledge.

Levy R 1968 'The effect of chlorpromazine on sentence structure of schizophrenic patients', Psychopharmacologia 13 426-432.

Lorenz M 1961 'Problems posed by schizophrenic language', Archives of General Psychiatry 4 603-610.

Manschreck TC, BA Maher, ME Rucklos \& MT White 1979 'The predictability of thought disordered speech in schizophrenic patients', British fournal of Psychiatry 134 595-601.

Rieber RW \& H Vetter 1994 'The problem of language and thought in schizophrenia: a review', fournal of Psycholinguistic Research 23 149-195.

Rochester S \& JR Martin 1979 Crazy Talk: A Study of the Discourse of Schizophrenic Speakers New York Plenum Press.

Rutter DR 1979 'The reconstruction of schizophrenic speech', British fournal of Psychiatry 134 356-359.

Sass LA 1992 Madness and Modernism: Insanity in the Light of Modern Art, Literature, and Thought New York Basic Books.

Schwartz S 1982 'Is there a schizophrenic language?', The Behavioural and Brain Sciences 5 579-626.

Shoham-Salomon V 1985 'Are schizophrenics' behaviours schizophrenic? What medically versus 
psychosocially oriented therapists attribute to schizophrenic persons', fournal of Abnormal Psychology 94 443-453.

Spohn HE 1973 'The case for reporting the drug status of patient subjects in experimental studies of schizophrenic psychopathology', Fournal of Abnormal Psychology 82 102-106.

von Domarus E 1946 'The specific laws of logic in schizophrenia, in JS Kasanin (ed) Language and Thought in Schizophrenia Berkeley CA University of California Press 104-114.

Wing JK 1978 Reasoning About Madness London Oxford University Press.

Wróbel J 1990 Language and Schizophrenia Amsterdam John Benjamins. 


\section{University Library}

\section{- M M N E R VA A gateway to Melbourne's research publications}

Minerva Access is the Institutional Repository of The University of Melbourne

Author/s:

Frow, J

Title:

Metaphor and metacommunication in schizophrenic language

Date:

2001-12-01

Citation:

Frow, J. (2001). Metaphor and metacommunication in schizophrenic language. Social Semiotics, 11 (3), pp.275-287. https://doi.org/10.1080/10350330120032502.

Publication Status:

Published

Persistent Link:

http://hdl.handle.net/11343/34311 